\title{
NOVO GÊNERO DE ANACOLINI E DESCRIÇÃO DOS MACHOS DE MYZOMORPHUS FLAVIPES E POEKILOSOMA CARINATIPENNE (COLEOPTERA, CERAMBYCIDAE, PRIONINAE)
}

\author{
Maria Helena M. Galileo ${ }^{1,3}$ \\ Miguel A. Monné2,3
}

\begin{abstract}
NEW GENUS OF ANACOLINI AND DESCRIPTION OF MALES OF MYZOMORPHUS FLAVIPES AND POEKILOSOMA CARINATIPENNE (COLEOPTERA, CERAMBYCIDAE, PRIONINAE). The new genus Hovorelus and its type-species, H. splendidus sp. nov., are described from Peru. The males of Myzomorphus flavipes Galileo, 1987 and Poekilosoma carinatipenne Lane, 1941 , both with sexual dimorphism, are described for the first time.
\end{abstract}

KEYWORDS. Anacolini, Hovorelus, Neotropical, new taxa, taxonomy.

\section{INTRODUÇÃO}

A tribo Anacolini, revista por Galileo (1987), contém 16 gêneros e 39 espécies neotropicais. O gênero Myzomorphus Dejean, 1835 reúne oito espécies e tem larga distribuição, com registros na América Central meridional, noroeste da América do Sul, Amazônia, Bolívia e Mata Atlântica. As espécies apresentam acentuado dimorfismo sexual, o que gerou alguns equívocos taxonômicos demonstrados pelas listas sinonímicas. Três espécies de Myzomorphus foram descritas com base em fêmeas: M. herteli Gilmour,1960 procedente de Sabanilla, Colômbia; M. amabilis (Tippmann, 1960) com registros para a região de Chaparé, Cochabamba, Bolívia e para Minas Gerais, Brasil; M. flavipes Galileo, 1987 procedente do Espírito Santo, Brasil.

O gênero Poekilosoma Audinet-Serville, 1832 foi transferido de Solenopterini para Anacolini na revisão de Galileo \& Martins (1993). Reúne a espécie-tipo P. ornatum (Dalman, 1823) e P. carinatipenne Lane, 1941, conhecida apenas pelo holótipo fêmea procedente de Recife, Pernambuco, Brasil.

Com base na coleção de Anacolini do Museu Nacional, Universidade Federal do Rio de Janeiro, Rio de Janeiro (MNRJ), um novo gênero é proposto e os machos de $M$. flavipes e $P$. carinatipenne são descritos pela primeira vez. Parte do material estudado está depositado no MCNZ, Museu de Ciências Naturais, Fundação Zoobotânica do Rio

1. Museu de Ciências Naturais, Fundação Zoobotânica do Rio Grande do Sul, Caixa Postal 1188, 90001-970 Porto Alegre, RS, Brasil.

2. Museu Nacional, Universidade Federal do Rio de Janeiro, Quinta da Boa Vista, São Cristóvão, 20940-040 Rio de Janeiro, RJ, Brasil

3. Pesquisador do CNPq. 
Grande do Sul, Porto Alegre e no MZSP, Museu de Zoologia, Universidade de São Paulo, São Paulo.

\section{Hovorelus gen. nov.}

Espécie-tipo, Hovorelus splendidus sp. nov.

Etimologia. O nome é uma homenagem ao entomólogo Frank Hovore, Santa Clarita, California, EUA, pelas inúmeras colaborações prestadas.

$\therefore$ Cabeça apenas mais larga que longa. Sutura frontal levemente sulcada, estendese pouco além da borda posterior dos olhos. Tubérculos anteníferos pouco projetados, arredondados. Olhos pequenos, granulação fina. Genas curtas, com borda arredondada.

Antenas flabeladas com onze artículos; mais longas que o corpo; flabelos dos antenômeros III-X estreitos, longos e, nos antenômeros basais, dispostos na margem externa e, gradativamente em direção aos antenômeros apicais, na margem ventral e na interna (a partir do antenômero VI); antenômeros III a XI micro-reticulados com sistema porífero inaparente. Protórax mais largo que longo, ângulo anterior com projeção arredondada, espinho curto próximo ao meio. Disco pronotal convexo; no centro da metade anterior, côncavo; de cada lado, próximo ao espículo lateral, intumescência alongada e oblíqua. Escutelo alongado, com a metade do comprimento do pronoto; margens laterais subparalelas na metade anterior e convergentes na metade posterior com a borda apical arredondada.

Prosterno convexo; processo prosternal largo, em forma de placa subovalada, algo projetado para o prosterno e sobreposto à região basal do processo mesosternal; superfície dessa área com pontuação e pilosidade grossas e densas. Mesosterno curto, processo mesosternal com região central côncava, lados subparalelos e borda apical emarginada. Metasterno com área central aplanada, em forma de placa semi-oval, com pontuação e pilosidade grossas e densas. Pernas sublineares, as anteriores e as médias subiguais em comprimento e, as posteriores, mais longas. Metafêmures encurvados na metade basal. Tíbias lineares. Tarsômeros curtos; estrutura esponjosa nos três primeiros tarsômeros.

Élitros recobrem totalmente o abdômen, úmeros arredondados, margens laterais levemente estreitadas para o ápice; ângulo marginal arredondado e ângulo sutural apenas demarcado. Último urosternito emarginado.

$\because$ Antenas curtas, alcançam o meio dos élitros. Antenômeros V-X com o ângulo externo-apical projetado com ápice arredondado; essas projeções, progressivamente mais longas em direção aos antenômeros apicais, mas o ápice não ultrapassa a borda apical do antenômero seguinte. Antenas com o tegumento micro-reticulado restrito ao entorno do ângulo externo-apical no antenômero III e em áreas progressivamente mais extensas em direção aos antenômeros apicais (metade apical do VI e inteiramente a partir do VII), com as microestrias mais pronunciadas e alongadas. Lados do protórax com espinho mais projetado e desenvolvido que o dos machos. Processo prosternal convexo e com superfície pontuada; metasterno levemente aplanado, sem pubescência diferenciada. Élitros com lados subparalelos. Último urosternito com emarginação acentuada.

Discussão. Considerando a filogenia dos gêneros de Anacolini (Galileo, 1987), Hovorelus tem afinidades com Prionapterus Guérin-Méneville, 1831, Udeterus Thomson, 1858 e Myzomorphus por compartilhar a sinapomorfia referente às pernas posteriores mais longas que as demais. O corpo alongado da fêmea também reforça a inclusão de 
Hovorelus nesse grupo, uma vez que no grupo-irmão, formado pelos gêneros Anacolus Latreille, 1825, Rhodocharis Lacordaire, 1869 e Charia Audinet-Serville, 1832, as fêmeas têm o corpo compacto e perfil convexo. A sinapomorfia do encurvamento dos fêmures posteriores em Udeterus e Myzomorphus também é observada em Hovorelus de forma menos acentuada. $\mathrm{O}$ escapo longo e com depressão dorsal é autapomórfico para Udeterus e fêmeas ápteras, metatarsos alongados com estrutura esponjosa reduzida são as autapomorfias de Prionapterus. As apomorfias referentes às modificações do processo prosternal e às do metasterno são compartilhadas por Myzomorphus e Hovorelus. As autapomorfias de Myzomorphus restringem-se aos flabelos dos antenômeros dos machos que são largos, foliáceos e ventrais e às metatíbias largas, foliáceas ou não. O tegumento com reflexos metálicos é autapomórfico para o gênero Hovorelus. Já a condição plesiomórfica dos élitros não-encurtados pode ser considerada como uma reversão do caráter.

\section{Hovorelus splendidus sp. nov.}

(Fig. 1)

$\therefore$ Tegumento castanho-escuro com intenso brilho metálico de reflexos esverdeados e/ou azulados (fig. 1). Antenas e pernas com brilho azul-metálico, exceto os fêmures amarelo-alaranjados. Metasterno e abdômen castanho-avermelhados com brilho metálico suave.

Cabeça com pontos esparsos; clípeo, genas e gula com tegumento reticulado e pontos grossos. Genas curtas, subtriangulares com ápice arredondado. Distância entre os lobos oculares superiores igual ao dobro da largura de um lobo.

Antenas ultrapassam o ápice elitral pelos dois últimos artículos. Escapo e pedicelo com tegumento micro-reticulado, pontos esparsos entremeados por pontos tuberculados; antenômeros III-XI com tegumento estriado longitudinalmente, micro-reticulado com pontos tuberculados, esparsos. Escapo tronco-cônico, com metade do comprimento do III; antenômero III apenas mais curto que o IV e subigual ao comprimento do VI; IV e V subiguais em comprimento; flabelos gradativamente mais longos em direção aos antenômeros apicais, flabelo do III estende-se até o meio do IV, o do IV e V atingem a borda apical do antenômero subseqüente, o dos demais ultrapassa a borda apical do antenômero seguinte em extensão gradativamente maior (flabelo do $\mathrm{X}$ atinge o terço apical do XI). Disco pronotal com pontos semi-grossos esparsos, mais concentrados junto às margens; pontos tuberculados ao longo das margens laterais. Escutelo e élitros com pontuação fina e esparsa. Face ventral com pubescência fina, amarelada, exceto no prosterno e, no abdômen, restrita aos lados. Pubescência densa e grossa no processo prosternal e na região central do metasterno. Fêmures com pontuação tuberculada, mais concentrada nos fêmures anteriores.

$\therefore$ Escapo com dois terços do comprimento do III e do IV; comprimento dos flagelômeros seguintes gradativamente decrescente em direção aos apicais, exceto o XI com o dobro do comprimento do X. Processo prosternal com superfície pontuada; metasterno pontuado com faixa ao longo da sutura de tegumento liso. Pubescência dos esternos torácicos fina, sedosa, amarelo-esbranquiçada. Pernas com tegumento mais liso, pontos e pêlos finos e esparsos. 


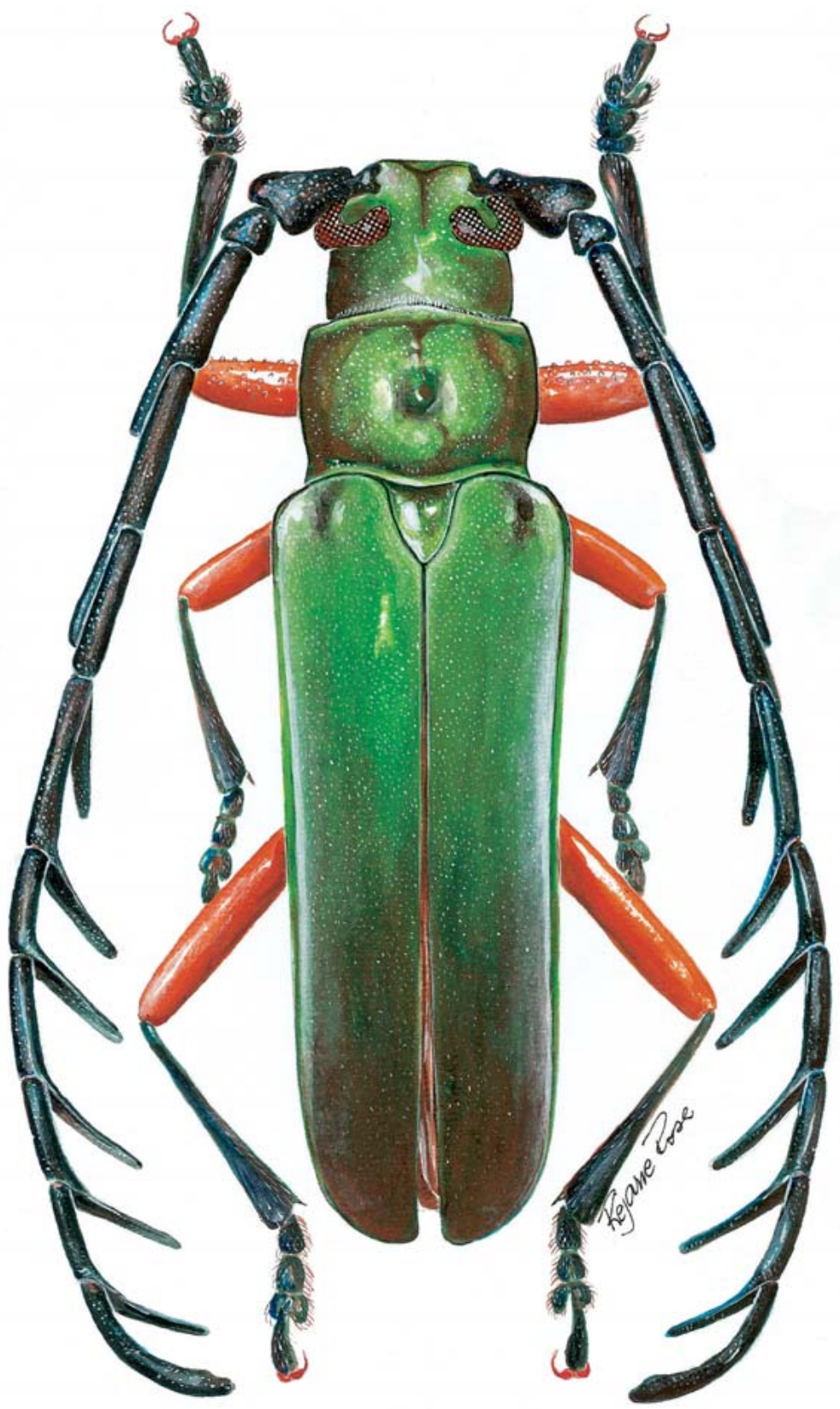

Fig. 1. Habitus, Hovorelus splendidus sp. nov., holótipo '‘, de Satipo, Junin, Peru, comprimento total, 21,0 $\mathrm{mm}$. 
Medidas, em mm, . ' Comprimento total 21,0-24,2/22,4-33,4; protórax: comprimento 3,0-3,7/3,0-4,2, maior largura 4,7-5,8/5,5-7,4; comprimento do élitro 14,8-17,2/17,5-23,3; largura umeral 5,9-7,0/7,1-9,8.

Material-tipo. PERU, Junin: Satipo, holótipo ‘’' XII.1940, Col. Campos Seabra (MNRJ); parátipos: ‘', 1940, Col. Campos Seabra (MCNZ ex-MNRJ); 2 ؛', X.1942, Col. J. M. Bosq (MNRJ); '-, X.1942, Col. J. M. Bosq (MCNZ ex-MNRJ); - X.1943, Col. Campos Seabra (MZSP ex-MNRJ); '-, XII.1940, Col. Campos Seabra (MNRJ); 3 -, VIII.1940, Col. Campos Seabra (MNRJ); '-, X.1940, Col. Campos Seabra (MNRJ); '-, 1940, Col. Campos Seabra (MNRJ); $2{ }^{\circ}-$, Col. Campos Seabra (MNRJ).

\section{Myzomorphus flavipes Galileo, 1987}

(Fig. 2)

Myzomorphus flavipes Galileo, 1987:595, '--, fig. 1013; MonnÉ, 1995:74 (cat.).

$\therefore$ Colorido geral variável; (1) tegumento preto a tonalidades mais avermelhadas e com áreas amareladas: região umeral, tubérculos anteníferos (ou não) borda anterior da cabeça, área clipeal, epístoma, mandíbulas, prosterno, mesosterno e centro do metasterno, pernas anteriores e médias, metade basal dos metafêmures, metatarsômeros III-V e urosternitos; (2) tegumento amarelo-alaranjado com áreas castanho-avermelhadas: occipício e região abaixo dos olhos, antenas, mancha no disco pronotal (extensão variável), escutelo, élitros exceto região umeral e bordas marginais e suturais, dois terços apicais das metatíbias e urotergitos. Pontuação grossa, densa, crivada. Pilosidade curta, concentrada no epístoma e nos esternos torácicos.

Cabeça mais larga que longa. Distância entre os tubérculos anteníferos maior que o triplo do diâmetro do escapo e distância interocular dorsal igual ao dobro da largura de um lobo. Antenas não ultrapassam o ápice do abdômen. Escapo tronco-cônico; mais curto que a metade do antenômero III que é o mais longo; comprimento dos demais antenômeros gradativamente menor. Antenômeros III-XI com flabelos na margem ventral, gradativamente mais longos em direção aos antenômeros apicais; borda apical do flabelo oblíqua na metade interna e arredondada na metade externa nos antenômeros III-V, XI e igualmente arredondadas nos demais antenômeros. Carena centro-longitudinal na face ventral dos antenômeros estendendo-se pelos flabelos.

Protórax com bordas laterais rebaixadas e projeção espiniforme logo após o meio: ângulos anteriores subarredondados e os posteriores marcados, sub-retos e pouco projetados. Disco pronotal pouco convexo sem protuberâncias evidentes, pontuação uniforme, sem áreas de tegumento liso. Processo prosternal desenvolvido, quase tão largo quanto longo, acoberta parcialmente o processo mesosternal. Pernas sublineares exceto as metatíbias (fig. 2) que são foliáceas e gradualmente alargadas para o ápice. Élitros deiscentes desde o escutelo, atingem a borda posterior dos urosternitos II ou III, ápices arredondados.

Dimensões, em mm, $\ulcorner$ Comprimento total 6,5-8,5; protórax: comprimento 1,5-2,0, maior largura 2,8-3,9; comprimento dos élitros 3,6-4,8; largura umeral 3,7-4,8.

Material examinado. Brasil, Espírito Santo: Linhares, $2{ }^{\prime},-$, IX.1971. B. Silva col., Col. Campos Seabra (MNRJ); ‘', X.1962, F. M. Oliveira col. (MCNZ ex-MZSP), ', X.1971, Roppa col. (MNRJ). 


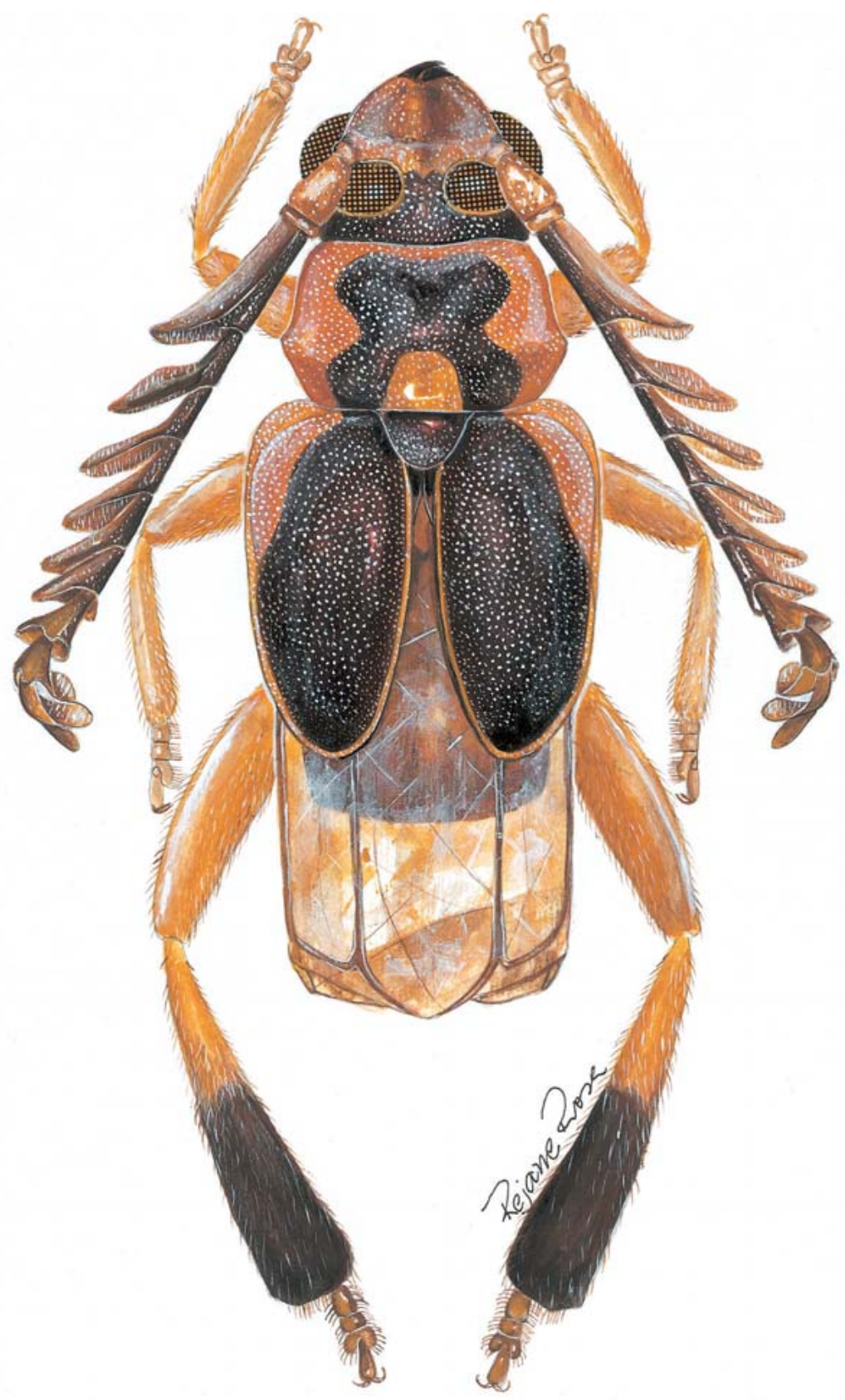

Fig. 2. Habitus, Myzomorphus flavipes Galileo, 1987, ‘', de Linhares, Espírito Santo, Brasil, comprimento (borda anterior a extremidade do élitro), 7,5 $\mathrm{mm}$.

Iheringia, Sér. Zool., Porto Alegre, 93(1):37-44, 30 de março de 2003 
Discussão. Myzomorphus flavipes juntamente com M. gounellei Lameere, $1912 \mathrm{e}$ M. amabilis (Tippmann, 1960) apresentam as metatíbias foliáceas. Difere de M. gounellei pelo pronoto uniformemente pontuado, sem intumescências; de M. amabilis (") pelas metatíbias alargadas gradativamente da base para o ápice. Em M. gounellei o disco pronotal apresenta duas intumescências com tegumento liso e, em M. amabilis (:) as metatíbias são bruscamente alargadas do meio para o ápice.

\section{Poekilosoma carinatipene Lane, 1941}

(Fig. 3)

Poekilosoma carinatipene LANE, 1941:152, fig. 1, '--; MonNÉ, 1995:77 (cat.).

$\therefore$ Tegumento castanho-escuro a preto, brilhante. Pontuação fina e esparsa na região dorsal da cabeça, nos lados do pronoto, nos esternos torácicos, nas pernas médias e posteriores e nos urosternitos. Epístoma densamente pontuado. Pernas anteriores com

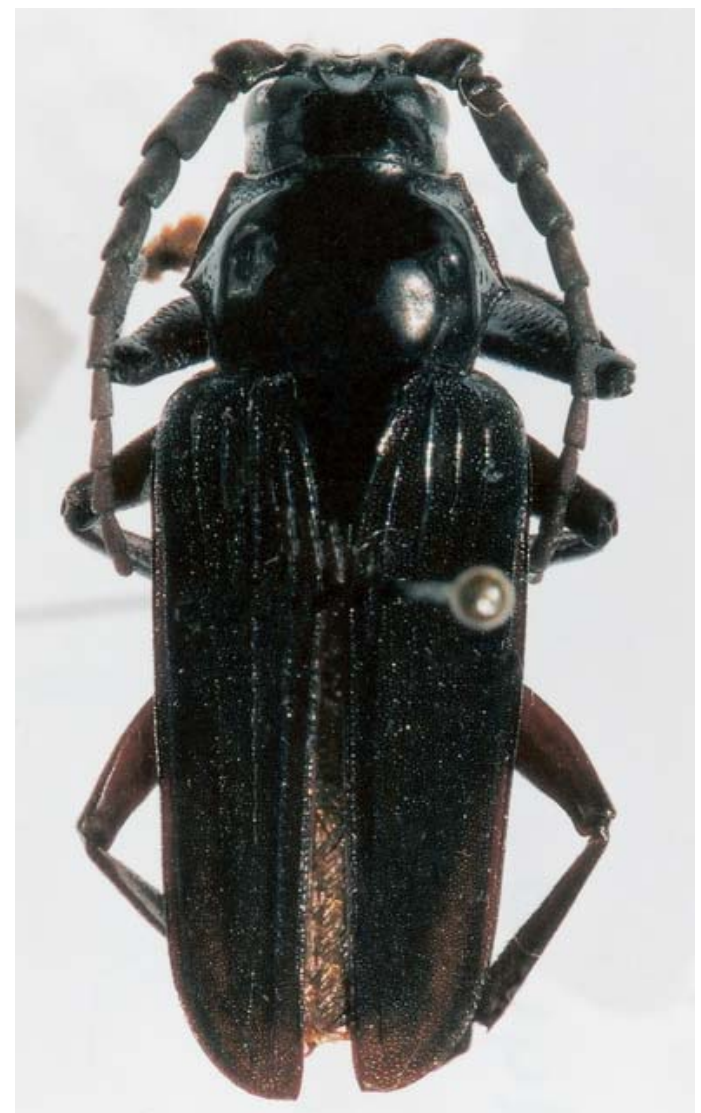

Fig. 3. Habitus, Poekilosoma carinatipene Lane, 1941, !', de Linhares, Espírito Santo, Brasil, comprimento total, $23,3 \mathrm{~mm}$. 
pontuação grossa e confluente. Élitros densa e uniformemente pontuados.

Fronte com depressão central. Gena curta, borda com pequena projeção triangular no centro. Antenas curtas, apenas ultrapassam os úmeros. Escapo subquadrangular. Antenômeros III-VI com ângulo externo pouco projetado. Antenômero III tão largo quanto o escapo, comprimento igual a 1,4 vezes o do IV; antenômeros IV-X com comprimento e largura gradativamente menores em direção aos apicais; XI tão longo quanto o III. Élitros com margens laterais levemente estreitadas para o ápice; borda apical arredondada e ângulo sutural demarcado. Cada élitro (fig. 3) com cinco carenas: a interna completa; as demais restritas ao terço basal dos élitros, a mais externa é vestigial. Último urosternito truncado no ápice.

Dimensões, em mm, $\backslash$. Comprimento total 23,3; protórax: comprimento 4,8, maior largura 7,3; comprimento dos élitros 15,8; largura umeral 8,3.

Material examinado. BRASIL, Espírito Santo: Linhares (50m), ‘', XI.1964; '-, XII.1966 (MNRJ).

Discussão. O macho de P. carinatipenne difere daquele de P. ornatum principalmente pela pontuação densa e contígua dos élitros intercalada por carenas, pelas antenas com $\mathrm{o}$ ângulo externo dos flagelômeros pouco projetado sem constituir flabelo. O dimorfismo sexual das espécies do gênero é marcante (GALILEO \& MARTINS, 1993) e justifica a redução do número e da extensão das carenas elitrais nos machos; a pontuação densa e contígua nos élitros sustenta a identificação do macho de P. carinatipenne.

Agradecimentos. À desenhista Rejane Rosa (MCNZ) pelas ilustrações; ao Antonio SantosSilva (MZSP) pela fotografia. Aos colegas Ubirajara R. Martins (MZSP) e Dilma Solange Napp (Universidade Federal do Paraná) pela leitura crítica.

\section{REFERÊNCIAS BIBLIOGRÁFICAS}

Galileo, M. H. M. 1987. Sistemática das tribos Meroscelisini e Anacolini nas Américas. II. Anacolini. Revta bras. Ent., São Paulo, 31(4):481-705.

Galileo, M. H. M. \& Martins, U. R. 1993. Revisão da tribo Solenopterini. Parte I. Transferência de Poekilosoma A.-Serville, 1832 e Calocomus A.-Serville, 1832; os gêneros Prosternodes Thomson, 1860 e Derancistrodes, gen. n. Revta bras. Ent., São Paulo, 37(1):79-99.

Lane, F. 1941. Sôbre o genero Poekilosoma Serville, 1832, com a descrição de uma nova espécie. Arch. Inst. Pesq. Agron., Recife, 3:149-156.

MonNÉ, M. A. 1995. Catalogue of the Cerambycidae (Coleoptera) of the western Hemisphere.

Part XXII. São Paulo, Sociedade Brasileira de Entomologia. 115p.

Recebido em 17.07.2002; aceito em 06.11.2002. 